\title{
UM EXPERIMENTO DE ANÁLISE EM FLUXO ENVOLVENDO REAÇÕES ENZIMÁTICAS E QUIMILUMINESCÊNCIA
}

Oldair Donizeti Leite e Orlando Fatibello-Filho

Departamento de Química, Universidade Federal de São Carlos, CP 676, 13560-970 São Carlos - SP

Fábio R. P. Rocha*

Instituto de Química, Universidade de São Paulo, CP 26077, 05513-970 São Paulo - SP

Recebido em 7/3/03; aceito em 13/8/03

\begin{abstract}
A FLOW ANALYSIS EXPERIMENT INVOLVING ENZYMATIC REACTIONS AND CHEMILUMINESCENCE. An experiment is proposed to introduce some fundamentals of flow analysis, chemiluminescence and kinetic monitoring of enzymatic reactions in undergraduate courses. Chemiluminescence detection is performed with a simple spectrophotometer equipped with a lab-made spiral flow cell constructed from a polyethylene tube. The hydrogen peroxide produced by the glucose oxidation in the presence of glucose oxidase is continuously monitored by the reaction with luminol in alkaline media in a flow injection system. The exercise allows also the discussion of important analytical features and the comparison with different optical methods of analysis.
\end{abstract}

Keywords: chemiluminescence; flow analysis; enzymatic reactions.

\section{INTRODUÇÃO}

O desenvolvimento da Química e os trabalhos de interface com áreas correlatas têm gerado grandes desafios para o ensino desta ciência. Um deles é a necessidade de incluir uma quantidade cada vez maior de conceitos, técnicas e informações importantes, sem que haja aumento do tempo dedicado às diferentes disciplinas. Uma alternativa para este problema é a proposição de experimentos que associem diferentes informações, permitindo explorar melhor o tempo disponível e, ao mesmo tempo, reduzir gastos. Essa estratégia também permite demonstrar que a compartimentalização da Química em diferentes áreas é artificial ${ }^{1}$, visto que a interpretação dos fenômenos com que o aluno se depara no dia-a-dia requer uma abordagem diferente, que utilize os conceitos químicos de maneira unificada e associada para seu entendimento. Os diferentes conceitos e técnicas introduzidos nas disciplinas de Química Analítica, por exemplo, são indispensáveis para a obtenção de informações relacionadas às outras disciplinas.

Neste contexto, é proposto um experimento para alunos de graduação em Química e áreas correlatas, que permite introduzir conceitos relacionados à análise em fluxo, quimiluminescência, reações enzimáticas e cinética química. A reação de oxidação da glicose na presença de glicose oxidase (GOD) foi estudada através do monitoramento da quimiluminescência da oxidação do luminol pelo peróxido de hidrogênio produzido. Uma cela em espiral construída com tubo de polietileno e adaptada a um espectrofotômetro simples permite efetuar medidas por quimiluminescência com equipamentos usuais em laboratórios de ensino.

\section{QUIMILUMINESCÊNCIA}

Luminescência é um termo empregado para descrever a emissão de radiação quando uma molécula ou átomo no estado excitado decai para o seu estado fundamental ${ }^{2}$. Os vários tipos de luminescência são caracterizados em função da fonte de energia empregada para se obter o estado excitado. Na quimiluminescência, a energia de excitação é proporcionada por uma reação química, sendo a emissão de radiação observada geralmente nas regiões do visível ou infravermelho próximo ${ }^{3,4}$. Esse processo pode ser simplificadamente representado pela Equação 1, onde A e $\mathbf{B}$ representam os reagentes, $\mathbf{A B} *$ o intermediário no estado excitado, $\mathbf{A B}$ o produto da reação, $\mathbf{h} \boldsymbol{v}$ a radiação emitida e $\mathbf{C}$ um catalisador. A partir da medida da intensidade de radiação emitida é possível a determinação da concentração dos reagentes ou do catalisador. Outras espécies podem ser quantificadas indiretamente, explorando reações que produzam as espécies reagentes ou catalisadores.

$\mathrm{A}+\mathrm{B} \stackrel{\mathrm{C}}{\longrightarrow} \mathrm{AB}^{*} \longrightarrow \mathrm{AB}+\mathrm{hv}$

Procedimentos analíticos baseados em medidas de quimiluminescência caracterizam-se por apresentar alta sensibilidade e ampla faixa de resposta linear. Uma das reações mais exploradas é a oxidação do luminol (5-amino-2,3-diidro-1,4-ftalazinediona) por peróxido de hidrogênio em meio alcalino, na presença do catalisador hexacianoferrato(III) de potássio. Diversas outras espécies podem ser empregadas como oxidantes (eg. $\left.\mathrm{ClO}^{-}, \mathrm{MnO}_{4}^{-}, \mathrm{Cr}_{2} \mathrm{O}_{7}^{2-}\right)$ ou catalisadores $\left(e g . \mathrm{Cu}^{2+}, \mathrm{Co}^{2+}, \mathrm{Fe}^{3+}\right)$ podendo ser também quantificadas explorando essa reação ${ }^{5}$. A aplicação é expandida pois redutores como frutose, ácido ascórbico e ácido úrico podem ser determinados indiretamente. Além disso, diversas reações enzimáticas produzem peróxido de hidrogênio e a reação de oxidação do luminol permite a quantificação indireta dos substratos destas reações.

Assim como ocorre com muitas outras reações envolvendo quimiluminescência, a oxidação do luminol na presença de catalisadores ocorre rapidamente e o tempo de emissão de radiação é bastante curto. Essas características, que dificultam a implementação destes procedimentos em batelada, os tornam atraentes para implementação em sistemas de análises em fluxo, nos quais as quantidades adicionadas de reagentes e o tempo disponível para a reação são perfeitamente reprodutíveis.

A ausência de uma fonte de radiação externa para excitação diferencia a quimiluminescência de outro fenômeno muito explorado

*e-mail: frprocha@iq.usp.br 
em Química, a fluorescência, e permite que a instrumentação para a implementação desta técnica seja simplificada. Apesar disto, equipamentos dedicados a medidas por quimiluminescência não são geralmente disponíveis em laboratórios didáticos e, em vista disto, esse tópico freqüentemente não é abordado em cursos de graduação. Entretanto, medidas por quimiluminescência podem ser feitas empregando espectrofotômetros simples, usualmente disponíveis em laboratórios de ensino. As adaptações necessárias podem ser efetuadas rapidamente e permitem uma discussão sobre os princípios e instrumentação envolvidos nas diferentes técnicas.

\section{REAÇÕES ENZIMÁTICAS}

Enzimas são proteínas que catalisam com grande eficiência as reações biológicas. São formadas por longas cadeias de aminoácidos unidas por ligações peptídicas e articuladas em estruturas tridimensionais ${ }^{6}$. Possuem em suas estruturas grupos polares tais como $\mathrm{COOH}, \mathrm{OH}, \mathrm{NH}_{2}, \mathrm{SH}$ e $\mathrm{CONH}_{2}$, que auxiliam na catálise enzimática $^{6}$. Sua eficiência catalítica e estrutura mais estáveis são observadas em meio aquoso. Enzimas são empregadas, por exemplo, em processos industriais, procedimentos analíticos, medicina, tecnologia de alimentos e biorremediação, devido à sua alta seletividade (em alguns casos, especificidade).

As reações enzimáticas envolvendo um único substrato $(\mathrm{S})$ podem ser representadas pela expressão geral (Equação 2), que envolve a formação de um intermediário (ES, denominado complexo enzimasubstrato). A velocidade de uma reação enzimática depende de diversos fatores, como as concentrações da enzima e do substrato e das condições reacionais (temperatura, acidez e intensidade iônica) 6 . Para uma dada concentração de enzima, a velocidade da reação aumenta com a concentração do substrato até atingir um valor limite, a partir do qual começa a ocorrer a saturação dos sítios ativos da enzima. A atividade enzimática é máxima em faixas estreitas de $\mathrm{pH}$ e temperatura (geralmente entre 25 e $40{ }^{\circ} \mathrm{C}$ ), diminuindo acentuadamente em valores inferiores e superiores. Em situações extremas de temperatura e pH pode-se observar a desnaturação das enzimas, processo geralmente irreversível que consiste na ruptura das estruturas da proteína. $\mathrm{O}$ estudo cinético da reação pode ser efetuado pelo monitoramento da concentração do produto formado ou do substrato consumido, permitindo estimar a velocidade máxima da reação, a eficiência biocatalítica e a afinidade da enzima pelo substrato. Maiores detalhes de aspectos cinéticos de reações enzimáticas foram didaticamente descritos ${ }^{7-9}$.

$\mathrm{E}+\mathrm{S} \rightleftharpoons \mathrm{ES} \longrightarrow \mathrm{E}+\mathrm{P}$

\section{SISTEMAS DE ANÁLISES EM FLUXO}

Os sistemas de análises em fluxo foram propostos com o objetivo de mecanizar procedimentos de análises químicas, reduzindo o envolvimento do operador, melhorando a precisão das medidas e aumentando o número de amostras que podem ser processadas por unidade de tempo. Em muitos casos, o consumo de reagentes e, conseqüentemente, a produção de resíduos são consideravelmente reduzidos em comparação aos procedimentos convencionais. Dentre as diversas modalidades, destacam-se os sistemas de análise por injeção em fluxo (FIA), devido à simplicidade e versatilidade. Nesses sistemas, alíquotas de amostra (e eventualmente de reagentes) são inseridas em uma solução que as transporta através do percurso analítico em direção ao detector. Durante o transporte, a amostra pode receber reagentes, sofrer diluições e participar de etapas de separação e concentração. As reações químicas geralmente não se completam, em virtude dos restritos tempos de residência (geralmente < 30 s). Entretanto, os resultados são em geral bastante precisos, devi- do à temporização altamente reprodutível. Em virtude do contato com a solução transportadora, ocorre a dispersão da amostra, originando gradientes de concentração. A dispersão é dependente das características físico-químicas das soluções (eg. viscosidade) e de fatores hidrodinâmicos (vazões, volume de amostra, comprimento e diâmetro dos tubos que constituem o percurso analítico). Como a medida é feita com a amostra em movimento em relação ao detector, é obtido um sinal transiente, cuja altura pode ser relacionada à concentração da espécie medida. Descrições mais detalhadas dos fundamentos e aplicações dos sistemas de análise por injeção em fluxo foram apresentadas em artigos com caráter didático ${ }^{10-13}$.

\section{PARTE EXPERIMENTAL}

\section{Equipamentos}

O sistema de análises em fluxo foi construído empregando um injetor proporcional com barra deslizante, tubos de polietileno de 0,8 mm de diâmetro interno e confluências feitas de acrílico. O injetor, que pode ser construído no próprio laboratório, consiste de 3 barras de acrílico presas por parafusos, sendo as barras laterais fixas e a central móvel ${ }^{14}$. A propulsão dos fluidos foi efetuada por uma bomba peristáltica (Ismatec IPC-4), equipada com tubos de Tygon de diferentes diâmetros. Alternativamente, poderiam ser utilizados compressores de ar do tipo bombas de diafragma de baixo custo, empregadas para oxigenação de aquários ${ }^{15}$. Para a medida da radiação emitida, foi empregado o detector de um espectrofotômetro monocanal (Femto, modelo 422), equipado com uma célula de fluxo construída com um tubo de polietileno (espessura $<0,1 \mathrm{~mm}$, diâmetro interno de $0,8 \mathrm{~mm}$ ) enrolado em espiral. Foram avaliadas celas com comprimentos de 50, 100 e $150 \mathrm{~cm}$. Um registrador potenciométrico (Cole-Parmer, cat. $\mathrm{n}^{\circ}$ 8376-30) foi empregado para o monitoramento dos sinais.

Um banho de água com temperatura controlada (Tecnal, modelo TE 184) foi utilizado para manter a temperatura da reação enzimática.

\section{Reagentes e soluções}

As soluções foram preparadas empregando água deionizada e reagentes com grau analítico. Solução de luminol 4,50 $\mathrm{mmol} \mathrm{L}^{-1}\left(\mathrm{R}_{1}\right)$ foi preparada dissolvendo-se 79,6 mg de 5-amino-2,3-diidro-1,4 ftalazinediona (Sigma) em $100 \mathrm{~mL}$ de solução de $\mathrm{K}_{2} \mathrm{CO}_{3} 0,2 \mathrm{~mol} \mathrm{~L}^{-1} \mathrm{e}$ ajustando o $\mathrm{pH}$ para 10,5 com $\mathrm{HCl}$. Solução de hexacianoferrato(III) de potássio 25,0 $\mathrm{mmol} \mathrm{L}^{-1}\left(\mathrm{R}_{2}\right)$ foi preparada dissolvendo-se 1,65 $\mathrm{g}$ de $\mathrm{K}_{3} \mathrm{Fe}(\mathrm{CN})_{6}$ em $200 \mathrm{~mL}$ de água. Soluções estoque de peróxido de hidrogênio $1,0 \mathrm{mmol} \mathrm{L}^{-1}$ foram preparadas diariamente, a partir de uma solução $30 \%(\mathrm{~m} / \mathrm{m})$ e padronizadas com permanganato de potássio. Soluções de referência de peróxido de hidrogênio em concentrações variando de 2,5 a $315,0 \mu \mathrm{mol} \mathrm{L}^{-1}$ foram preparadas por diluições da solução estoque.

Solução de glicose $3,90 \times 10^{-3} \mathrm{~mol} \mathrm{~L}^{-1}$ foi preparada dissolvendo-se 140,0 mg de $\beta$-D-glicose (Sigma) em $200 \mathrm{~mL}$ de solução tampão ácido acético/acetato de sódio $0,05 \mathrm{~mol} \mathrm{~L}^{-1}(\mathrm{pH} 5,1)$ em um balão volumétrico. Solução estoque de enzima foi preparada dissolvendo-se $25 \mathrm{mg}$ (470 U) de glicose oxidase (Sigma) em $5 \mathrm{~mL}$ da mesma solução tampão acetato. Esse volume de solução é suficiente para implementar o experimento com diferentes grupos de alunos, podendo ser efetuadas 50 repetições.

\section{Diagrama de fluxos e procedimento}

\section{Determinação de peróxido de hidrogênio}

A cela de fluxo foi construída enrolando-se em espiral $100 \mathrm{~cm}$ 
de um tubo de polietileno, da maneira ilustrada na Figura 1. Esta cela foi posicionada em frente à janela do detector do espectrofotômetro, sendo fixa por fitas adesivas. $\mathrm{O}$ feixe de radiação do espectrofotômetro foi interrompido posicionando-se um anteparo em frente à janela de saída.

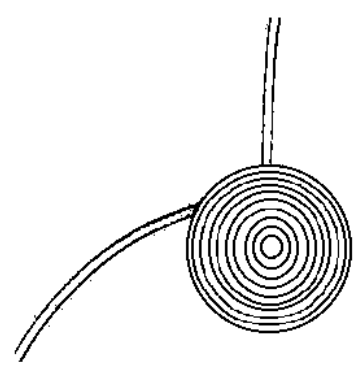

Figura 1. Representação da cela de fluxo construída com tubo de polietileno (100 cm, 0,8 mm d.i.) empregada nas medidas por quimiluminescência

O diagrama de fluxos do módulo de análise empregado para a determinação de peróxido de hidrogênio é apresentado na Figura 2. Na posição mostrada, uma alíquota de $150 \mu \mathrm{L}$ da solução de peróxido (A) é inserida no transportador $\left(\mathrm{H}_{2} \mathrm{O}\right)$ e recebe por confluência as soluções de luminol em meio alcalino $\left(\mathrm{R}_{1}\right.$, ponto de confluência $\left.\mathrm{x}\right) \mathrm{e}$ de hexacianoferrato(III) de potássio $\left(\mathrm{R}_{2}\right.$, ponto de confluência y). A cela de fluxo é conectada ao módulo de análise no ponto de confluência y, a partir do qual se inicia a emissão de radiação devida à oxidação do luminol. Na posição alternativa do injetor, a alça de amostragem é preenchida por uma nova alíquota de solução de $\mathrm{H}_{2} \mathrm{O}_{2}$, enquanto o fluxo da solução $\mathrm{R}_{1}$ é direcionado ao seu reservatório, visando minimizar o consumo de luminol.

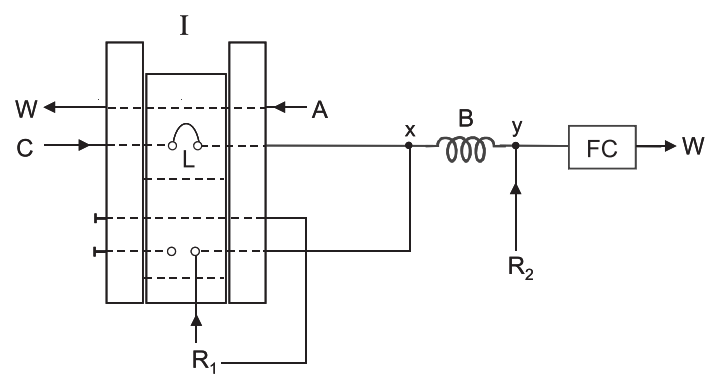

Figura 2. Diagrama de fluxos para a determinação de $\mathrm{H}_{2} \mathrm{O}_{2}$. I - injetor; $L$ alça de amostragem $(150 \mu \mathrm{L}) ; B$ - reator helicoidal $(20 \mathrm{~cm}) ; \mathrm{FC}$ - cela de fluxo em espiral posicionada em frente ao detector; $x, y$ - pontos de confluência; $\mathrm{C}$ - transportador $\left(\mathrm{H}_{2} \mathrm{O}\right), 4,5 \mathrm{~mL} \mathrm{~min} \mathrm{~m}^{-1} ; \mathrm{A}$ - solução de referência ou solução proveniente do reator enzimático; $R_{1}$ - solução de luminol 4,50 mmol L $\mathrm{m}^{-1}$ em $\mathrm{K}_{2} \mathrm{CO}_{3} 0,2 \mathrm{~mol} \mathrm{~L}^{-1}$, pH 10,5 (1,5 mL min $\left.{ }^{-1}\right) ; R_{2}$ - solução de hexacianoferrato(III) de potássio $25,0 \mathrm{mmol} \mathrm{L}^{-1}\left(1,5 \mathrm{~mL} \mathrm{~min}^{-1}\right) ; \mathrm{W}$ - recipiente de descarte

As medidas de intensidade de radiação emitida (em triplicata) foram baseadas nas alturas dos sinais obtidos com o registrador potenciométrico ajustado em um fundo de escala de $50 \mathrm{mV}$, posteriormente convertidas em valores de diferença de potencial. $\mathrm{O}$ ruído da linha base $\left(R_{B}\right)$ foi estimado mantendo-se o injetor na posição de inserção de amostra após a medida dos sinais e alterando-se o fundo de escala do registrador para $1 \mathrm{mV}$.

\section{Monitoramento da reação enzimática}

A reação enzimática foi processada em um becker de vidro de $400 \mathrm{~mL}$ imerso em banho de água com temperatura ajustada em $(35,0$ $\pm 0,2)^{\circ} \mathrm{C}$. A alíquota de $200 \mathrm{~mL}$ da solução de glicose $3,90 \times 10^{-3}$ mol L ${ }^{-1}$ foi previamente imersa no banho de água por $15 \mathrm{~min}$. Em seguida adicionou-se $0,100 \mathrm{~mL}$ da solução estoque de glicose oxidase (94 U/mL) e o cronômetro foi imediatamente acionado. O módulo de análise representado na Figura 2 foi empregado para o monitoramento do peróxido de hidrogênio formado na reação. Um tubo inserido no interior do becker permitia a amostragem de alíquotas da mistura reacional, que preenchiam a alça de amostragem (L). A inserção das amostras era efetuada em intervalos de $1 \mathrm{~min}$.

\section{RESULTADOS E DISCUSSÃO}

\section{Medida de quimiluminescência}

Uma das principais dificuldades relacionadas à implementação de procedimentos baseados em medidas por quimiluminescência é maximizar a quantidade de radiação detectada, uma vez que a emissão ocorre em todas as direções. Desta forma, diversas configurações de celas têm sido propostas, sendo usual o emprego de celas em espiral, posicionadas em frente ao detector (usualmente uma fotomultiplicadora). Essas celas são construídas em vidro ou quartzo e não são facilmente acessíveis em laboratório didáticos. Neste experimento, é proposto o emprego de uma cela construída enrolando-se um tubo de polietileno em espiral (Figura 1). Esse material é satisfatoriamente transparente à radiação emitida pela oxidação do luminol $\left(\lambda_{\text {MAX }}=425 \mathrm{~nm}\right)$ e pode ser adquirido a baixo custo (US\$ 0,40/metro) no mercado nacional (por exemplo, em lojas especializadas em materiais cirúrgicos). A cela pode ser construída pelos próprios alunos no laboratório, dispensando mão de obra especializada para a confecção das celas em vidro ou quartzo e possibilitando introduzir discussões sobre a geometria adequada da cela. As adaptações necessárias, apesar de simples, permitem iniciar discussões sobre instrumentação e funcionamento de diferentes equipamentos analíticos.

A cela em espiral pode ser adaptada em frente à janela do detector de um espectrofotômetro convencional (equipamento usual em laboratórios didáticos) e permite a implementação de procedimentos baseados em quimiluminescência também a custo relativamente baixо. Os resultados apresentados foram obtidos com um espectrofotômetro que emprega um fotodiodo como detector. Embora pudesse ser alcançada sensibilidade superior empregando uma fotomultiplicadora, o desempenho desse detector de menor custo é bastante satisfatório. Alternativamente, fotodetectores de custo relativamente baixo poderiam ser empregados para a medida dos sinais ${ }^{16}$, permitindo também a introdução de conceitos relacionados à instrumentação e eletrônica.

Na Tabela 1, são apresentados resultados obtidos variando-se o comprimento do tubo de polietileno empregado na construção da cela de medida. Foi também avaliado o efeito do recobrimento da

Tabela 1. Efeito do comprimento da cela sobre a sensibilidade das medidas por quimiluminescência. Concentração de $\mathrm{H}_{2} \mathrm{O}_{2}=$ $245 \mu \mathrm{mol} \mathrm{L}{ }^{-1}$

\begin{tabular}{cc}
\hline Comprimento da cela $(\mathrm{cm})$ & Intensidade de sinal $(\mathrm{mV})$ \\
\hline 50 & $2,3 \pm 0,1$ \\
100 & $11,9 \pm 0,1$ \\
$100^{*}$ & $13,5 \pm 0,3$ \\
150 & $8,9 \pm 0,2$ \\
\hline
\end{tabular}

*cela recoberta com papel alumínio 
face externa da cela de detecção com papel alumínio, visando maximizar (por reflexão) a quantidade de radiação que atingia o detector. Os melhores resultados foram obtidos para a cela construída com $100 \mathrm{~cm}$ de tubo, recoberta por papel alumínio. Enquanto para comprimentos maiores de tubo o número de hélices na espiral era maior e a radiação emitida nas hélices externas não alcançava o detector, para comprimentos menores uma fração representativa da radiação era emitida após a cela de medida.

\section{Determinação de peróxido de hidrogênio}

A cela de fluxo de polietileno (Figura 1) foi adaptada a um sistema de análise por injeção em fluxo (Figura 2) para a determinação de peróxido de hidrogênio, explorando a reação de oxidação de luminol em meio alcalino na presença do catalisador hexacianoferrato(III) (Equação 3). A radiação produzida (hv) foi proporcional à concentração de peróxido de hidrogênio em solução.

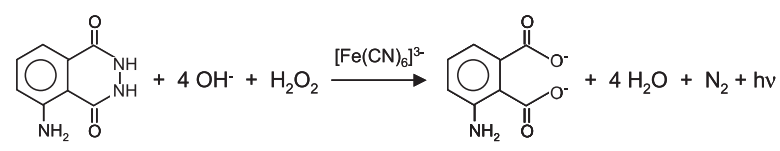

Na Figura 3, são apresentados alguns sinais transientes obtidos com soluções de referência de peróxido de hidrogênio. Resposta linear foi obtida entre 2,50 e $315 \mu \mathrm{mol} \mathrm{L}^{-1} \mathrm{de}_{2} \mathrm{O}_{2}$, descrita pela equação: Sinal analítico $(\mathrm{mV})=0,188+0,129 \mathrm{C}_{\mathrm{H}_{2} \mathrm{O}_{2}}\left(\mu \mathrm{mol} \mathrm{L} \mathrm{L}^{-1}\right), \mathrm{r}=0,999$. Esta equação permite a determinação de $\mathrm{H}_{2} \mathrm{O}_{2}$ em amostras com concentração desconhecida, a partir da medida da intensidade dos sinais. Com base no coeficiente angular da curva $(\mathrm{m})$ e na estimativa do ruído da linha base $\left(\mathrm{R}_{\mathrm{B}}\right)$, o limite de detecção foi calculado em 1,0 $\mu \mathrm{mol} \mathrm{L} \mathrm{L}^{-1}$ a nível de confiança de $99,7 \%$ (3 $\left.\times \mathrm{R}_{\mathrm{B}} / \mathrm{m}\right)$. Este valor corresponde à mínima concentração de $\mathrm{H}_{2} \mathrm{O}_{2}$ que gera um sinal analítico significativamente diferente do sinal de branco, no nível de confiança empregado para a estimativa. O coeficiente de variação (desvio padrão relativo) foi estimado em $1,2 \%$, para 10 medidas empregando uma solução de $\mathrm{H}_{2} \mathrm{O}_{2} 100 \mu \mathrm{mol} \mathrm{L}^{-1}$. A partir dos sinais transientes mostrados na Figura 3, pode-se estimar uma freqüência de amostragem de 70 determinações/h. Devido à adição intermitente

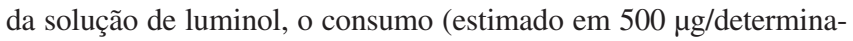
ção) é $60 \%$ inferior ao que seria observado caso a adição do reagente fosse contínua. $\mathrm{O}$ emprego dessa estratégia permite introduzir discussões sobre configurações de sistemas de análises em fluxo e sobre a necessidade de minimizar o consumo de reagentes e a produção de resíduos.

O experimento proposto permite discutir o significado e as estratégias para a estimativa de importantes parâmetros analíticos, como sensibilidade, limite de detecção, faixa de resposta linear e precisão. É também possível discutir sobre a seletividade do procedimento, na presença de espécies oxidantes e redutoras, que poderiam incrementar ou atenuar a intensidade de quimiluminescência, causando interferências positivas ou negativas, respectivamente. Desta forma, é possível discutir sobre o aumento de seletividade que pode ser alcançado mediante o emprego de reações seletivas, como a oxidação de glicose na presença de oxigênio e da enzima glicose oxidase. Vantagens dos sistemas de análises em fluxo em relação aos procedimentos em batelada (eg. alta freqüência de amostragem, menor consumo de reagentes e melhor precisão) podem também ser discutidas.

\section{Monitoramento da reação enzimática}

A combinação da alta sensibilidade da detecção por quimiluminescência à seletividade dos sistemas enzimáticos constitui uma fer-

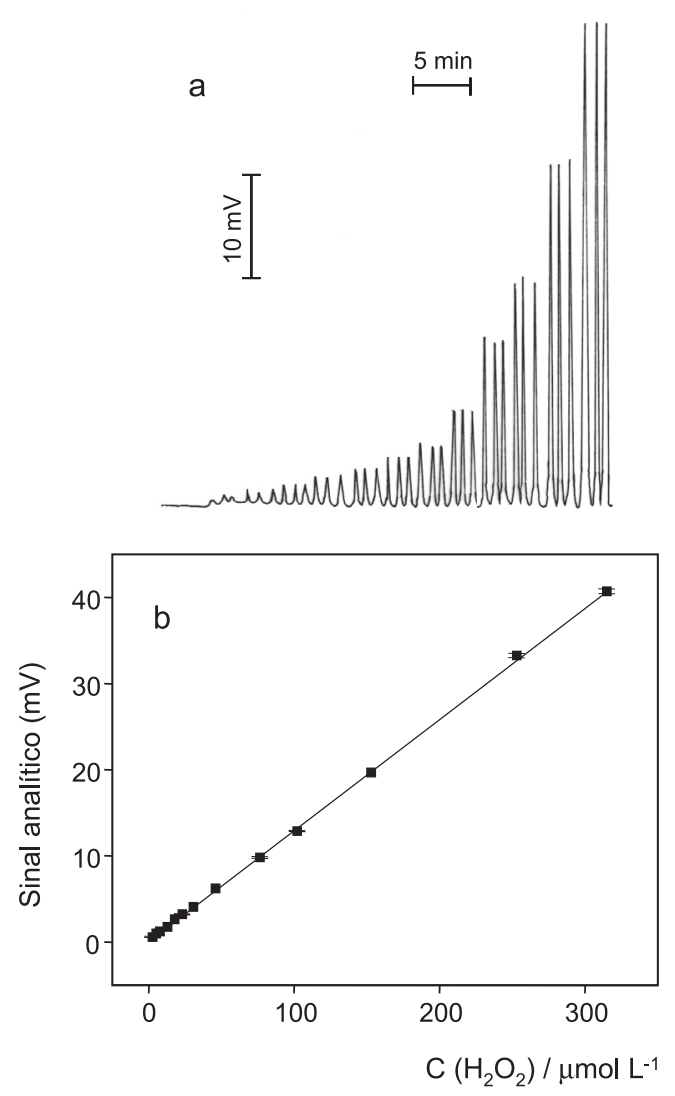

Figura 3. (a) Sinais transientes obtidos para soluções de $\mathrm{H}_{2} \mathrm{O}_{2}$ entre 2,50 e $315 \mu \mathrm{mol} \mathrm{L}{ }^{-1}$; (b) curva analítica relacionando sinal analítico e concentração de $\mathrm{H}_{2} \mathrm{O}_{2}:$ sinal analítico $(\mathrm{mV})=0,188+0,129 \mathrm{C}_{\mathrm{H}_{2} \mathrm{O}_{2}}\left(\mu \mathrm{mol} L^{-1}\right), r=0,999$

ramenta bastante útil em pesquisas, mas ainda pouco explorada em práticas de ensino. $\mathrm{O}$ experimento proposto permite esta combinação, através do monitoramento de um dos produtos (peróxido de hidrogênio) produzido durante a oxidação da glicose. A glicose oxidase é uma das enzimas mais empregadas em Química Analítica, apresentando características importantes, como boa estabilidade quando comparada a outras enzimas, ser disponível com alto grau de pureza a preço acessível, não necessitar de cofatores e apresentar alta seletividade ao substrato $\beta$-D-glicose. A glicose é oxidada pelo oxigênio na presença dessa enzima, produzindo ácido glicônico e peróxido de hidrogênio (Equação 4). $\mathrm{O} \mathrm{H}_{2} \mathrm{O}_{2}$ produzido é então quantificado através da reação de oxidação do luminol (Equação 3).

$\beta$-D-glicose $+\mathrm{O}_{2}+\mathrm{H}_{2} \mathrm{O} \stackrel{\text { GOD }}{\longrightarrow}$ ácido D-glicônico $+\mathrm{H}_{2} \mathrm{O}_{2}$

A atividade enzimática (eficiência biocatalítica) é usualmente expressa em Unidades/g enzima. No caso da glicose oxidase, uma unidade proporciona a oxidação de $1 \mu \mathrm{mol}$ de $\beta$-D-glicose a ácido glicônico e peróxido de hidrogênio por min a pH 5,1 e $35^{\circ} \mathrm{C}{ }^{17}$. Entretanto, quando a reação é conduzida em meio saturado por oxigênio, pode ocorrer um aumento de 50 a $100 \%$ da atividade da enzima.

Os resultados obtidos no monitoramento do peróxido de hidrogênio gerado na oxidação da glicose, bem como os valores esperados considerando a atividade da enzima segundo o fabricante são mostrados na Figura 4. A partir dos sinais transientes obtidos em intervalos de 1,0 min (Figura 4a) foram determinadas as concentrações de peróxido de hidrogênio no meio reacional (Figura 4b), utilizando-se a equação da curva analítica mostrada na Figura $3 b$. As 
concentrações de $\mathrm{H}_{2} \mathrm{O}_{2}$ calculadas considerando-se a atividade enzimática informada pelo fabricante ${ }^{17}$ foram concordantes com aquelas determinadas experimentalmente no intervalo de tempo inicial da reação (Figura 4b). Nos tempos reacionais iguais ou superiores a 7 min, as concentrações de peróxido de hidrogênio e de glicose permanecem praticamente constantes e iguais a $235 \mu \mathrm{mol} \mathrm{L} \mathrm{L}^{-1} \mathrm{e}$ $3,88 \mathrm{mmol} \mathrm{L}^{-1}$, respectivamente. Esse comportamento indica a inibição da atividade enzimática, provavelmente pelo peróxido de hidrogênio formado ${ }^{18-20}$, visto que o substrato (glicose) foi empregado em excesso. A forma reduzida da enzima é particularmente sensível à concentração de peróxido de hidrogênio e, em concentrações elevadas a enzima pode ser inativada por oxidação de grupos metionina nas proximidades ou no sítio ativo da enzima ${ }^{18}$.

Diversos aspectos relacionados à cinética de reações enzimáticas podem ser abordados. Através das medidas nos instantes iniciais da reação é possível estimar a atividade enzimática. Ademais, outros conceitos podem ser abordados experimentalmente, como o efeito da concentração inicial de enzima e/ou substrato sobre a velocidade de reação e o efeito de diversos outros fatores sobre a atividade catalítica, como $\mathrm{pH}$, temperatura, presença de ativadores ou inibidores
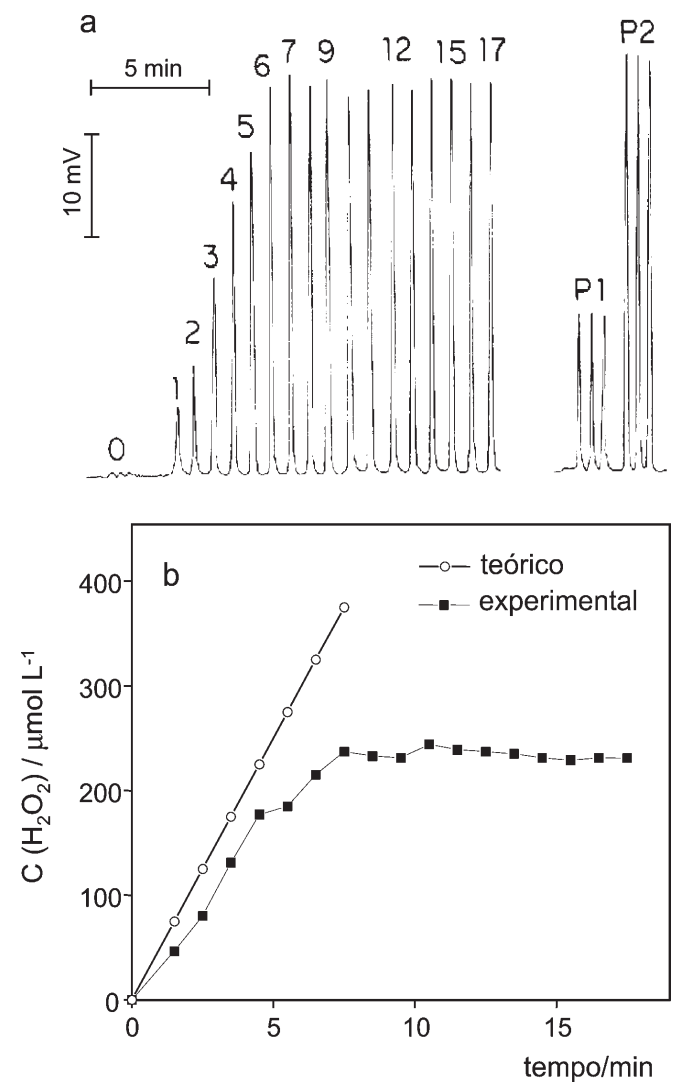

Figura 4. Monitoramento do peróxido de hidrogênio formado pela oxidação de glicose na presença da enzima glicose oxidase. (a) Os números 1-17 representam os sinais transientes obtidos amostrando alíquotas da mistura reacional em intervalos de 1 min. $P_{1}$ e $P_{2}$ - sinais transientes obtidos para soluções contendo 102 e $255 \mu \mathrm{mol} \mathrm{L} \mathrm{L}^{-1}$ de $\mathrm{H}_{2} \mathrm{O}_{2}$. (b) Variação da concentração de $\mathrm{H}_{2} \mathrm{O}_{2}$ em função do tempo de reação determinada experimentalmente e estimada a partir da atividade informada pelo fabricante enzimáticos ${ }^{18}$. Empregando-se sistemas de análises em fluxo com detecção por quimiluminescência é possível determinar o valor da constante de Michaelis-Menten para a reação enzimática ${ }^{21}$. Neste caso, a concentração da enzima e o tempo de reação devem ser mantidos constantes, enquanto a concentração de substrato é variada. Estes estudos podem ser realizados por diferentes grupos de alunos e os resultados encontrados discutidos criticamente com a classe. Considerando-se as quantidades envolvidas de reagentes, o custo por experimento é inferior a US\$ 0,30 .

\section{CONCLUSÕES}

O experimento proposto permite introduzir conceitos relacionados à análise em fluxo e detecção por quimiluminescência, através de uma aplicação analítica (incluindo a possibilidade de se discutir o significado e os procedimentos para a estimativa de características analíticas importantes) e do monitoramento cinético de reações enzimáticas. Desta forma, é adequado para ser implementado nas disciplinas de análise instrumental, Físico-Química ou Bioquímica, podendo ser executado em um período de $4 \mathrm{~h}$, incluindo o preparo das soluções. Além disso, é possível a discussão sobre aspectos instrumentais envolvidos em diferentes métodos ópticos de análise (espectrofotometria e fluorescência). Essas características vêm de encontro à necessidade de se desenvolver experimentos que englobem um número maior de conceitos, visando evitar a omissão de assuntos importantes por falta de tempo e, por outro lado, reduzir os custos associados às práticas desenvolvidas em laboratórios didáticos.

\section{AGRADECIMENTOS}

Os autores agradecem à FAPESP, CNPq e CAPES pelas bolsas e auxílios concedidos e a P. R. M. Correia pelas sugestões apresentadas.

\section{REFERÊNCIAS}

1. Senise, P. E. A.; Quim. Nova 1982, 5, 137.

2. Dodeigne, C.; Thunus, L.; Lejeune, A.; Talanta 2000, 51, 415.

3. Schroeder, H. R.; Yeager, F. M.; Anal. Chem. 1978, 50, 1114.

4. Merenyi, G.; Lind, J.; Eriksen, T. E.; J. Biolumin. Chemilumin. 1990, 5, 53.

5. Ferreira, E. C.; Rossi, A. V.; Quim. Nova 2002, 25, 1003.

6. Lehninger, A. L.; Princípios da Bioquímica, $2^{\mathrm{a}}$ ed., Savier: São Paulo, 1986.

7. Ault, A.; J. Chem. Educ. 1974, 51, 381.

8. Ochs, R. S.; J. Chem. Educ. 2000, 77, 1453.

9. Johnson, K. A.; J. Chem. Educ. 2002, 79, 74.

10. Nóbrega, J. A.; Rocha, F. R. P.; J. Chem. Educ. 1997, 74, 560.

11. Reis, B. F.; Giné, M. F.; Kronka, E. A. M.; Quim. Nova 1989, 12, 82.

12. Reis, B. F.; Quim. Nova 1996, 19, 51.

13. Rocha, F. R. P.; Martelli, P. B.; Reis, B. F.; Quim. Nova 2000, 23, 119.

14. Rocha, F. R. P.; Nóbrega, J. A.; Chem. Educator 1999, 4, 179. Publicação eletrônica http://chemed.boisestate.edu.

15. Matos, R. C.; Gutz, I. G. R.; Angnes, L.; Fontenele, R. S.; Pedrotti, J. J.; Quim. Nova 2001, 24, 795.

16. Borges, E. P.; Fernandes, E. N.; Rocha, F. R. P.; Reis, B. F.; Quim. Nova 2002, 25, 1191.

17. http://www.sigmaaldrich.com, acessada em Fevereiro 2003

18. Kleppe, K.; Biochemistry 1966, 5, 139.

19. Krishnaswamy, S.; Kittrell, J. R.; Biotechnol. Bioeng. 1978, $20,821$.

20. Malikkides, C. O.; Weiland, R. H.; Biotechnol. Bioeng. 1982, 24, 2419.

21. Guilbault, G. G.; Analytical Uses of Immobilized Enzymes, Marcel Dekker: New York, 1984, p. 1-56. 